
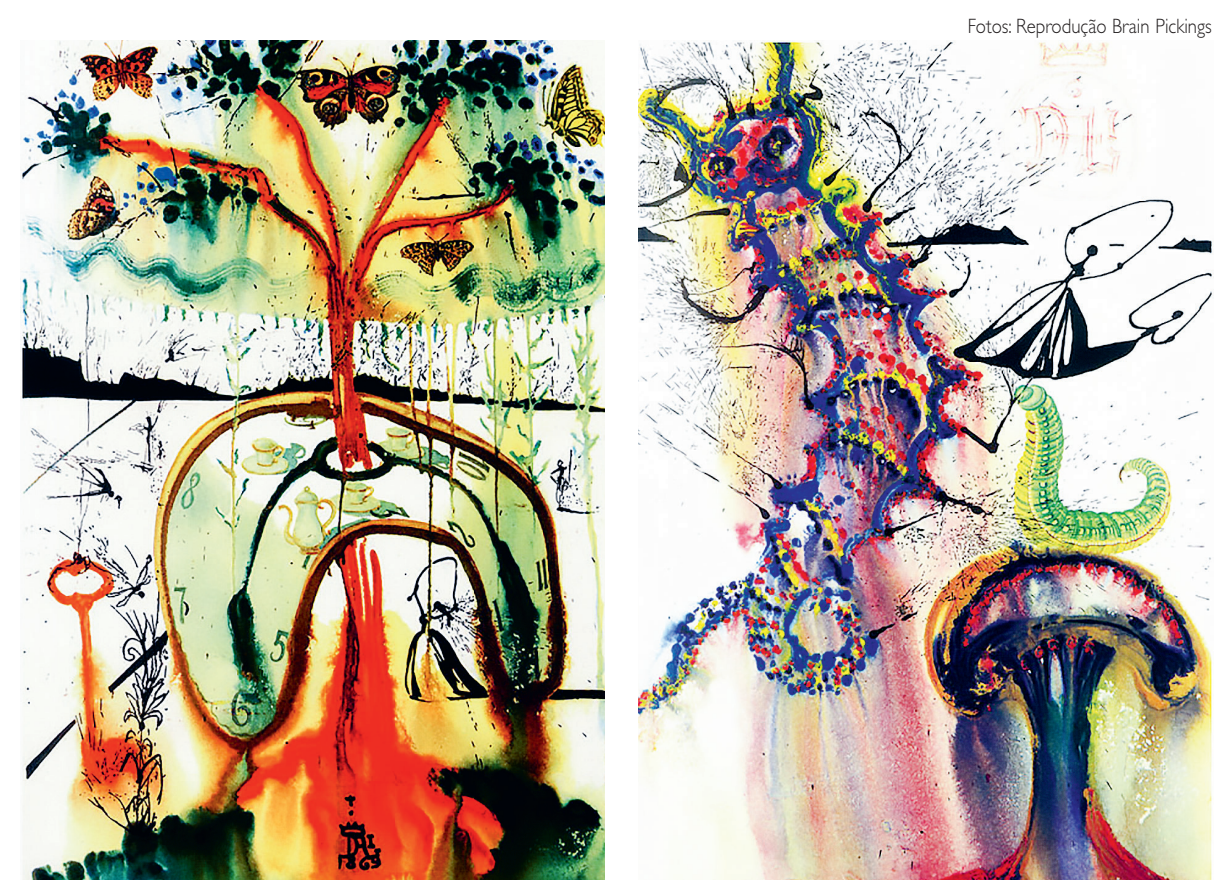

"Alice" é um dos livros mais ilustrados em todos os tempos

LITERATURA

\title{
HÁ I5O ANOS ERA PUBLICADA A PRIMEIRA EDIÇÃO DO CLÁSSICO DE LEWIS CARROLL
}

Naquele verão de 1862 o passeio de barco com a família do reverendo Henry Liddell parecia uma boa ideia para Charles Dodgson, escritor e matemático da Universidadede Oxford, na Inglaterra. Tímido e retraído entre os adultos, Dodgson ficava mais à vontade com crianças. No bote que flutuava ao sol da tarde, não demorou muito, no entanto, para que Alice, uma das filhas do padre, fosse tomada pelo tédio. Acostumado a inventar histórias para entreter seus irmãos menores, o escritor começou a contar a história de outra Alice, que, também entediada, passa a perseguir um coelho apressado, acaba mergulhando em sua toca e vai parar em outro país. Charles Dodgson é o nome verdadeiro de Lewis Carroll, autor de Alice no pais das maravilhas, clássico da literatura infanto-juvenil, um dos livros mais traduzidos de todos os tempos, cuja primeira edição completa 150 anos em 2015. Em todo o mundo, exposições, espetáculos de teatro e de dança, comemoram o aniversário de Alice.

A Lewis Carroll Society criou um site na internet (http://lewiscarroll- resources.net/2015/index.html) com uma lista de eventos em todo o mundo. Na capital mineira, por exemplo, será comemorado o Carrollsday, no Memorial Vale, no dia 4 de julho. O evento envolve literatura e poesia nonsense, artes plásticas, moda, música e performances. Em Londres, na Inglaterra, o Museu da Infância (V\&A Museum of Childhood) apresenta uma exposição com roupas, fotografias e objetos mostrando como a menina, com seu vestido rodado e os sapatos-boneca, foi, ao longo das inúmeras ediçōes do livro, uma lançadora de tendências "O visual de Alice" (The Alice look), em cartaz até novembro deste ano, tem ainda edições raras do livro, ilustrações de campanhas publicitárias e, é claro, desfiles de moda. "Alice é uma fonte inesgotável de criatividade e invenção, tanto no mundo das imagens quanto nas ideias. Foi um dos livros que mais influenciaram as artes em todos os tempos, permitindo reinvençôes em diversas mídias e linguagens", afirma a artista gráfica Adriana Peliano, fundadora e presidente da Sociedade Lewis Carroll do Brasil.

HISTÓRIA PARA VER “Mas, afinal, de que serve um livro sem figuras nem diálogos?”, pergunta Alice para sua irmã que lia, recostada no jardim. Uma característica que certamente contribuiu para o grande sucesso desse livro são suas ilustrações. Alice é também um livro para ver. Os primeiros desenhos foram feitos pelo próprio Carroll, em um manuscrito que o autor deu de presente para Alice Liddell e cuja versão digital está disponível no site da Biblioteca 
Britânica. Vários artistas ilustraram o livro, alguns famosos como Salvador Dalí que, em 1969, recebeu uma encomenda para ilustrar uma edição especial do clássico e produziu 12 heliogravuras, uma para cada capítulo do livro. "Alice no país das maravilhas é um dos livros mais ilustrados de todos os tempos. Até recentemente esse universo iconográfico era fortemente marcado pelas ilustrações originais de Tenniel", explica. "Nas últimas duas décadas, no entanto, cada vez mais essa influência vem sendo desafiada em trabalhos que buscam um diálogo mais aberto e enigmático com a obra, superando uma abordagem ligada à descrição das cenas e personagens", acredita Peliano.

No Brasil, o livro ganhará uma reedição especial pela editora Zahar. As ilustraçôes originais de John Tenniel, de 1865, foram revisitadas por Adriana Peliano por meio de colagens criadas digitalmente. "Mais que uma técnica, a colagem é um jogo conceitual em que o conhecido muda de lugar, e temos que sair do lugar comum e da nossa zona de conforto. Somos então confrontados por uma nova lógica que propõe enigmas e quebra-cabeças num convite ao sonho e ao nonsense", conta a artista.

UM MUNDO DE PONTA CABEÇA Escrito originalmente para uma criança, Alice encanta públicos de todas as idades porque mistura elementos fantásticos, em um mundo onde pouca coisa é impossível, com uma fina crítica política da sociedade inglesa do século XIX. "Lewis Carroll colocou de cabeça para baixo a cul- tura vitoriana, expondo o mal-estar, a impostura e a esterilidade de uma sociedade fechada e repressiva”, escreveu Nicolau Sevcenko, em posfácio para a edição de Alice no país das maravilhas, de 2009, da Cosac Naify. Para ohistoriador, as criaturas fantásticas do livro - que fazem as crianças se sentirem em casa - encarnam as instituições e os personagens de uma sociedade rígida e pouco flexível. Alice se rebela contra eles, se mostrando ora indignada, ora espantada: "Onde já se viu dar a sentença antes de julgar se o acusado é culpado ou não?", diz, em um dos tantos momentos em que questiona a autoridade. "Lewis satiriza e Alice desacata, para a diversão e a desforra dos leitores", completou Sevcenko. A passagem de Alice para o "país das maravilhas” é uma longa queda. A menina chega a adormecer enquanto desce. Sonhar que estamos caindo é uma das experiências oníricas mais recorrentes nos seres humanos. Para Suelt Gevertz, psicanalista da Uni-

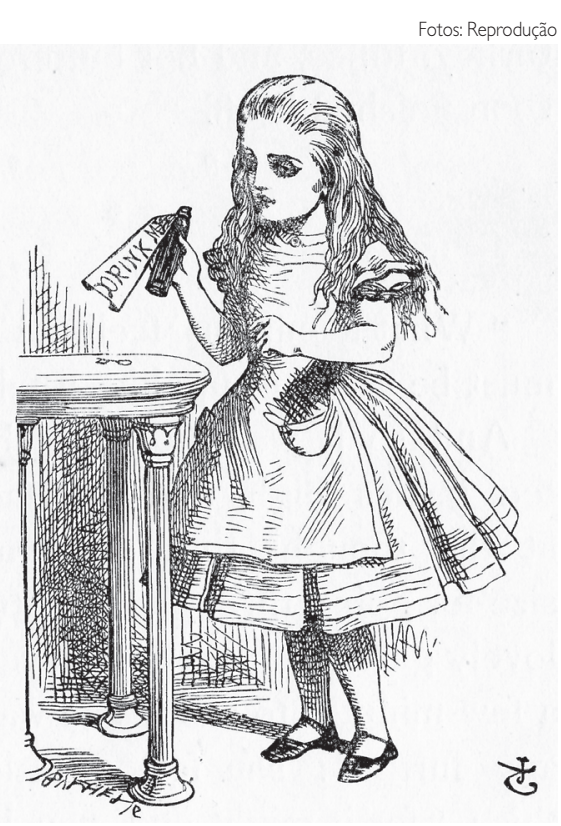

versidade Federal de São Paulo (Unifesp), a história de Alice comporta diversos elementos oníricos. "O livro pode ser visto como um sonho que elabora questôes do crescimento que são comuns a todas as pessoas. A passagem do tempo, o desejo impossível, amor, amizade, hierarquia”, afirma. Segundo ela, essa é uma das razões para a história permanecer atual e atraente 150 anos depois de seu lançamento. "É um livro tão fascinante que pode ser visto de diferentes maneiras", complementa.

Sonho ou alucinação, para Adriana Peliano, Alice é uma fonte infinita de criatividade e invenção, "uma história capaz de levar o leitor a outros mundos, mundo de 'alicinações'”, pontua a artista. "É um livro de perguntas, uma obra habitada por enigmas e paradoxos complexos, mas também íntimos de muitos leitores, que se identificam profundamente com os desafios de Alice e com os personagens que ela encontra em sua viagem".

Patrícia Mariuzzo
Primeiras ilustrações do livro feitas pelo desenhista John Tenniel em 1865

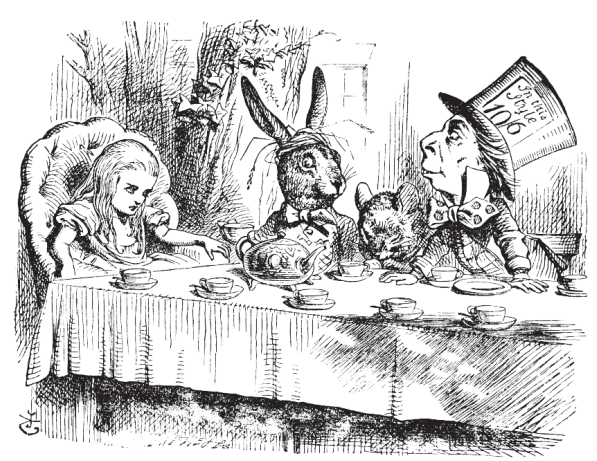

